\title{
Load Matching in a Direct-Coupled Photovoltaic System-Application to Thevenin's Equivalent Loads
}

\author{
A. Balouktsis, ${ }^{1}$ T. D. Karapantsios, ${ }^{2}$ K. Anastasiou, ${ }^{3}$ A. Antoniadis, ${ }^{4}$ and I. Balouktsis ${ }^{1}$ \\ ${ }^{1}$ Department of Informatics \& Communications, Technological Educational Institution of Serres, Terma Magnesias, \\ P.O. Box 62124, Serres, Greece \\ ${ }^{2}$ Department of Chemistry, Aristotle University of Thessaloniki, University Box 116, 54124 Thessaloniki, Greece \\ ${ }^{3}$ Department of Informatics and Computer Technology, Technological Educational Institution of Lamia, \\ 3rd Km ONR Lamias-Athinas, 35100, Lamia, Greece \\ ${ }^{4}$ Department of Natural Resources \& Environment, Technological Educational Institution of Crete, Romanou 3 , \\ 73133 Chania, Greece
}

Received 25 February 2005; Revised 24 August 2005; Accepted 5 September 2005

\begin{abstract}
A methodology is developed for the assessment of load matching and further estimation of the optimum photovoltaic (PV) arrays arrangement over a prolonged period of time. The method calls for the calculation of the appropriate effectiveness factor defined as the ratio of the load energy over the maximum energy that can be produced by the PV array for a specific time period. The effectiveness factor depends on the PV array characteristics, the load characteristics, and the solar irradiance conditions. To produce realistic predictions for the effectiveness factor and the PV arrays arrangement with validity over long periods of time, the present statistical model describing irradiance employs a stochastic variation of solar radiation over a long period of time and not just a fixed diurnal variation as traditionally done in the past. Simulations are performed for the case of Thevenin's equivalent loads. In order to generalize the analysis, the simulation results are presented in a reduced form based on the values of the voltage and current corresponding to the maximum power of the PV array. The results are presented in multiple-curve comprehensive plots, which allow to determine the optimum photovoltaic array panel's arrangement without engaging sophisticated mathematical calculations.
\end{abstract}

Copyright (c) 2006 A. Balouktsis et al. This is an open access article distributed under the Creative Commons Attribution License, which permits unrestricted use, distribution, and reproduction in any medium, provided the original work is properly cited.

\section{INTRODUCTION}

In many stand-alone PV systems, the solar modules array is designed to power specific single loads, such as lights (resistive loads), electromechanical loads coupled to dc motors, electrolysis loads, and so forth [1]. Two different load configurations are currently in use for PV systems. One is the direct-coupled systems which are simple and reliable, but do not operate at the maximum power operating point of the array due to the continuous variation of solar radiation. The other uses a maximum power point tracker (MPPT) to maintain the PV array at a voltage for which it produces maximum power. The latter is the most efficient configuration of the two but it is less reliable in many occasions. The quality of load matching in a PV system determines the system performance and its degree of utilization. An optimum PV panels' arrangement results in more accurate sizing, reduction of the rating of the subsystems, and maximum utilization of the costly solar array generator.
Several studies investigated the direct-coupled PV-load configuration and obtained useful information regarding the adaptability of a PV system to various loads [2-6]. The design methodology in these studies was either based on the diurnal variation of solar radiation so their results could not be safely applied over a period of time or produced results for specific input radiation time series and so their results were not of general validity.

Electric power production by a PV system depends greatly on insolation, which varies continuously with time. Therefore, the design of such a system involves a stochastic parameter and differs from the design of a conventional power production system. This work aims to provide a generalized methodology for analyzing the direct coupling of a PV system to Thevenin's equivalent loads. The optimum design of the system is based on the maximization of the effectiveness factor that is defined as the ratio of the load input energy to the PV array maximum energy over a time period. The advantage of this approach lies in the fact that it takes 
into account the variation of solar radiation over a long time period and not in just one day as previous studies has done [2-4].

The developed mathematical model clearly demonstrates the various design parameters that have a significant contribution on the response of the system. It is of great importance to realize in advance which parameters have the most profound effect, how sensitive the system is to them, and what are their relative magnitudes. The extensive interrelationships among the various equations make the model complicated to evaluate, and it is by no means easy to draw quantitative information just by inspecting the equations. To provide insight into the effects of these parameters, the descriptive equations are solved for Thevenin's equivalent loads using conventional numerical analysis techniques. In order to generalize the results, a per unit system approach is adopted based on the array maximum power point parameters. Results show that an optimum photovoltaic array panel's arrangement can be achieved by simplified calculations without the need of using sophisticated simulations and cumbersome mathematical analyses.

\section{MODEL DEVELOPMENT}

A single PV unit is a nonlinear electric power source whose characteristic equation depends chiefly on the intensity of solar radiation and to a lesser extent on temperature. Putting together in series and in parallel several such units results in a PV system whose characteristic equation depends, along with the above, also on the arrangement of the connected units. Thus, the characteristic equation of a PV system has the general form

$$
I=f_{\mathrm{PV}}(U, G, T, p, s),
$$

where $I$ is the current of the system, $U$ is the voltage of the system, $G$ is the solar radiation, $T$ is the temperature of the PVs, $s$ is the number of the PV units connected in series $(s-$ chains), and $p$ is the number of the $s$-chains connected in parallel.

The characteristic equation of an electric load is of the form

$$
I=f_{L}(U) .
$$

When the load is coupled directly to the PV system, then the power delivered to the load is the product of the voltage times the current of the system:

$$
P_{L}=I(G, T, p, s) \cdot U(G, T, p, s) .
$$

The magnitudes of $U$ and $I$ are obtained from the solution of the system of (1) and (2).

Considering that the variation of the PV temperature is chiefly a function of radiation, the average power for this period is

$$
\bar{P}_{L}=\int P_{L}(G, p, s) \cdot f_{G}(G) d G,
$$

where $f_{G}(G)$ is the probability density function of solar

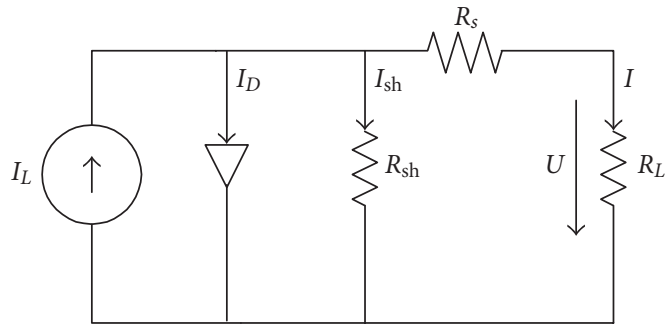

FIgURE 1: Equivalent electrical circuit of a solar unit.

radiation. In a similar manner, the average maximum power produced by the PVs can be estimated from (1):

$$
\begin{gathered}
P_{\mathrm{PV}}^{\max }=(I \cdot U)_{\max }, \\
\bar{P}_{\mathrm{PV}}^{\max }=\int P_{\mathrm{PV}}^{\max }(G) \cdot f_{G}(G) d G .
\end{gathered}
$$

The ratio of the two quantities is defined as an effectiveness factor:

$$
n_{\mathrm{ef}}=\frac{\bar{P}_{L}}{\bar{P}_{\mathrm{PV}}^{\max }}
$$

The optimum matching of the PV system to the coupled load corresponds to the particular combination of in-series $(s)$ and in-parallel $(p)$ connected units that yield the maximum $n_{\mathrm{ef}}$.

\subsection{Characteristic equation of a PV system}

The electrical behavior of a PV unit is represented in the equivalent electric circuit of Figure 1.

The relationship between current and voltage is [7]

$$
\begin{aligned}
I & =I_{L}-I_{D}-I_{\mathrm{sh}} \\
& =I_{L}-I_{0}\left\{\exp \left[\frac{U+I R_{S}}{U_{T}}\right]-1\right\}-\frac{U+I R_{S}}{R_{\mathrm{sh}}},
\end{aligned}
$$

where $I_{L}$ is the short-circuit current in (A), $I_{D}$ is the diode current of the equivalent circuit, $I_{0}$ is the inverse polarization current in (A), $I$ is the load current in (A), $U$ is the load voltage in $(\mathrm{V}), R_{s}$ is the series resistance in $(\Omega), R_{\mathrm{sh}}$ is the shunt resistance in $(\Omega)$, and $U_{T}$ is the thermal voltage in $(\mathrm{V})$.

In practice and particularly for the case of single crystalline silicon cells, the resistance $R_{\mathrm{sh}}$ is much higher than $R_{s}$ and therefore (7) can be reduced as follows:

$$
I=I_{L}-I_{D}=I_{L}-I_{0}\left\{\exp \left[\frac{U+I R_{s}}{U_{T}}\right]-1\right\}
$$

Parameters $I_{L}, I_{0}, R_{s}$, and $U_{T}$ depend on solar radiation and the temperature of the PV unit. A method to determine these four parameters is presented by Duffie and Beckman [7]. This method is based on information for $I$ and $U$ given by the manufacturer of a PV unit for irradiance, $G_{\text {ref }}$, at a reference 
TABLE 1: Nominal parameters of PV units SM55 (Siemens).

\begin{tabular}{lccccc}
\hline$N_{s}=36$ cells & $I_{\mathrm{sc}, \text { ref }}=3.45 \mathrm{~A}$ & $I_{\mathrm{mp}, \text { ref }}=3.15 \mathrm{~A}$ & $\mu_{U, \mathrm{oc}}=-0.077 \mathrm{~V} /{ }^{\circ} \mathrm{C}$ & $T_{a, \text { ref }}=293 \mathrm{~K}$ & $G_{\mathrm{ref}}=1000 \mathrm{~W} / \mathrm{m}^{2}$ \\
\hline$P_{\max }=55 \mathrm{~W}$ & $U_{\mathrm{oc}, \mathrm{ref}}=21.7 \mathrm{~V}$ & $U_{\mathrm{mp}, \text { ref }}=17.4 \mathrm{~V}$ & $\mu_{I, \mathrm{sc}}=1.2 \mathrm{~mA} /{ }^{\circ} \mathrm{C}$ & $T_{c, \text { NOCT }}=319 \mathrm{~K}$ & $G_{\mathrm{NOCT}}=800 \mathrm{~W} / \mathrm{m}^{2}$ \\
\hline
\end{tabular}

temperature, $T_{\text {ref }}$, (e.g. Table 1 ), and is described briefly by the following relations:

$$
\begin{gathered}
I_{L, \text { ref }}=I_{\mathrm{sc}, \text { ref }}, \\
U_{T, \text { ref }}=\frac{\mu_{U, \mathrm{oc}} T_{c, \text { ref }}-U_{\mathrm{oc}, \mathrm{ref}}+E_{q} N_{s}}{\mu_{\mathrm{I}, \mathrm{sc}} T_{c, \text { ref }} / I_{L, \text { ref }}-3}, \\
I_{0, \text { ref }}=\frac{I_{L, \text { ref }}}{\exp \left(U_{\mathrm{oc}, \text { ref }} / U_{T, \text { ref }}\right)-1}, \\
R_{s, \text { ref }}=\frac{U_{T, \text { ref }} \ln \left(1-I_{\mathrm{mp}, \text { ref }} / I_{L, \text { ref }}\right)-U_{\mathrm{mp}, \text { ref }}+U_{\mathrm{oc}, \text { ref }}}{I_{\mathrm{mp}, \mathrm{ref}}} .
\end{gathered}
$$

The subscripts oc, sc, mp, and ref refer to open circuit, short circuit, maximum power, and reference conditions, respectively. In addition, $E_{q}$ is the energy gap of silicon $(\mathrm{eV}), N_{s}$ is the number of cells connected in series in a single unit of the PV system, and $\mu_{U, \mathrm{oc}}, \mu_{I, \mathrm{sc}}$ are the temperature coefficients of the open circuits voltage and closed circuits current, respectively. For varying insolation and temperature conditions, the above parameters change according to the following relations:

$$
\begin{gathered}
\frac{U_{T}}{U_{T, \text { ref }}}=\frac{T_{C}}{T_{C, \text { ref }}}, \\
I_{L}=\frac{G}{G_{\text {ref }}}\left[I_{L, \text { ref }}+\mu_{I, \mathrm{sc}}\left(T_{C}-T_{C, \text { ref }}\right)\right], \\
I_{0}=I_{0, \text { ref }}\left(\frac{T_{C}}{T_{C, \text { ref }}}\right)^{3} \exp \left[\frac{E_{q} N_{s}}{U_{T}}\left(1-\frac{T_{C, \text { ref }}}{T_{C}}\right)\right], \\
R_{s}=R_{s, \text { ref. }}
\end{gathered}
$$

The unit temperatures, $T_{C}$ and $T_{C \text {,ref }}$, are computed from the relation

$$
T_{C}=T_{\alpha}+G \cdot \frac{T_{C, \text { NOCT }}-T_{\alpha}}{G_{\text {NOCT }}} \cdot\left(1-\frac{n_{c}}{\tau \alpha}\right)
$$

using $G$ and $T_{a}$ or $G_{\text {ref }}$ and $T_{a \text {,ref }}$, respectively. In (17) $T_{a}$ is the ambient temperature, the subscript NOCT refers to the unit temperature for nominal operation, $n_{c}$ is the efficiency of the unit at NOCT conditions, and $\tau \alpha$ is the product of the unit coefficients of transmittance and absorption.

In brief, the evaluation of the characteristic equation of a PV system is as follows: first, (9) to (12) are used to estimate the values of the four aforementioned parameters at reference conditions. Next, these values are adjusted to the actual operating conditions with (13) to (17). Finally, the system current, $I$, is calculated from (18) which is derived from (8) accounting for the PV units that are connected in parallel $(p)$ and in series $(s)$ :

$$
I=p \cdot I_{L}-p \cdot I_{0}\left\{\exp \left[\frac{U+I \cdot s / p \cdot R_{s}}{s \cdot U_{T}}\right]-1\right\}
$$

\subsection{Voltage-current characteristics of Thevenin's equivalent loads}

Loads of different kind can be coupled directly to a PV system. In its most general form, the load characteristic equation is given by (2). Specifically, for Thevenin's equivalent loads, (2) can be written as

$$
U=I \cdot R_{\mathrm{th}}+U_{\mathrm{th}}
$$

where $R_{\text {th }} \kappa \alpha_{1} U_{\text {th }}$ are the Thevenin equivalent resistance and voltage, respectively, that hold for load circuits that may combine voltage sources with resistances. Such loads are a pure ohmic load, an electrolytic load, a battery, a battery combined with an ohmic load, and so forth.

\subsection{Variability of solar radiation}

In order to describe the temporal variability of daily solar radiation, the equations proposed by Bendt et al. [8] are employed. These equations provide the probability distribution of the daily clearness index, $K_{T}=G_{d} / G_{o}$, over a period of time when the average clearness index is $\bar{K}_{T}$ :

$$
F\left(K_{T}\right)=\frac{\exp \left(\gamma K_{T, \min }\right)-\exp \left(\gamma K_{T}\right)}{\exp \left(\gamma K_{T, \min }\right)-\exp \left(\gamma K_{T, \max }\right)}
$$

where $\gamma$ is computed from the following relations:

$$
\begin{gathered}
\bar{K}_{T} \\
=\frac{\left(K_{T, \text { min }}-1 / \gamma\right) \exp \left(\gamma \cdot K_{T, \text { min }}\right)-\left(K_{T, \text { max }}-1 / \gamma\right) \exp \left(\gamma \cdot K_{T, \text { max }}\right)}{\exp \left(\gamma \cdot K_{T, \text { min }}\right)-\exp \left(\gamma \cdot K_{T, \text { max }}\right)}, \\
\gamma=-1.498+\frac{1.184 \xi-27.182 \exp (-1.5 \xi)}{K_{T, \text { max }}-K_{T, \text { min }}}, \\
\xi=\frac{K_{T, \text { max }}-K_{T, \text { min }}}{K_{T, \text { max }}-\bar{K}_{T}}, \\
K_{T, \text { max }}=0.6313+0.267 \bar{K}_{T}-11.9\left(\bar{K}_{T}-0.75\right)^{8} \\
K_{T, \text { min }}=0.05
\end{gathered}
$$

where $\bar{K}_{T}, K_{T, \max }$, and $K_{T, \min }$ are the average, maximum, and minimum daily clearness index for a specific location and time period, whereas $G_{d}$ and $G_{o}$ are the daily and extraterrestrial solar radiation, respectively.

Figures $2 \mathrm{a}$ and $2 \mathrm{~b}$ display the probability distribution $((20))$ and the corresponding probability density function of various average clearness index values. 


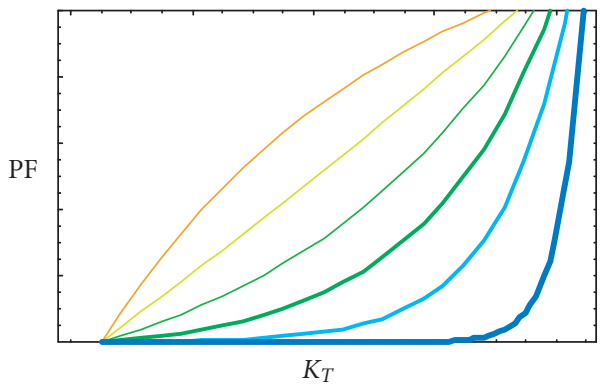

(a)

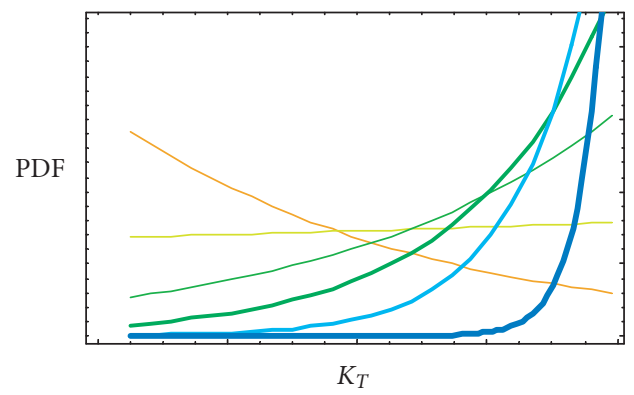

(b)

FIGURE 2: (a) probability distribution and (b) probability density function versus clearness index. The different curves correspond to different average clearness index values.

The corresponding diurnal variation of solar radiation obeys the relations [7]

$$
\begin{gathered}
r_{t}=\frac{G}{G_{d}}, \\
r_{t}=\frac{\pi}{24}(z+b \cos \omega) \frac{\cos \omega-\cos \omega_{s}}{\sin \omega_{s}-\left(\pi \omega_{s} / 180\right) \cos \omega_{s}}, \\
z=0.409+0.5016 \sin \left(\omega_{s}-60\right), \\
b=0.6609-0.4767 \sin \left(\omega_{s}-60\right),
\end{gathered}
$$

where $G$ is the hourly radiation. The quantities $\omega$ (hour angle) and $\omega_{s}$ (sunrise hour angle) are common solar engineering parameters that can be computed from analytical expressions, for example, [7]. It must be noted that the sunrise hour angle depends greatly on the latitude of the measuring location.

Total irradiance on the PV array plane is calculated using an isotropic model for both the diffuse irradiation and the ground reflected irradiation. Calculations by this model take into account the location latitude and the tilt of the array plane. Details on the above can be found in classic solar engineering books, for example, [7].

\section{SIMULATION RESULTS}

A simulation algorithm has been developed in order to examine the effectiveness factor of a PV system directly coupled to Thevenin's equivalent loads and also optimize an appropriate (per unit) design parameter defined as the ratio of load resistance to equivalent resistance of the PV system:

$$
R_{p u}=\frac{R_{\mathrm{th}}}{R_{\mathrm{eq}, \mathrm{PV}}},
$$

where the equivalent resistance of the PV system is given as

$$
R_{\mathrm{eq}, \mathrm{PV}}=\frac{U_{\mathrm{mp}, \mathrm{PV}}-U_{\mathrm{th}}}{I_{\mathrm{mp}, \mathrm{PV}}}=\frac{s \cdot U_{\mathrm{mp}, u}-U_{\mathrm{th}}}{p \cdot I_{\mathrm{mp}, u}},
$$

where $U_{\mathrm{mp}, \mathrm{PV}}\left(U_{\mathrm{mp}, u}\right)$ and $I_{\mathrm{mp}, \mathrm{PV}}\left(I_{\mathrm{mp}, u}\right)$ are the voltage and current for the maximum power of the PV system (unit) when the solar radiation is equal to the hourly radiation at solar noon for the specific location, season, clearness index, and tilt of PV units.

For the determination of the maximum power point and the operation point of the PV system, the bisection method was employed. Simulations were performed for the PV units SM55 (Siemens) the nominal parameters of which are given in Table 1.

Simulations variables were $U_{\text {th }}=40 \mathrm{~V}, R_{\text {th }}(5 \Omega, 15 \Omega$, and $25 \Omega)$, latitude $\left(20,30,40\right.$, and $\left.50^{\circ}\right)$, daily clearness in$\operatorname{dex}(0.3,0.4,0.5,0.6$, and 0.7$)$, and PV tilts $\left(20,40\right.$, and $\left.50^{\circ}\right)$. Tests are performed for a representative month of each season, January, April, July, and October, namely.

The significance of each of the above variables on the effectiveness factor, $n_{\mathrm{ef}}$, and design parameter, $R_{p u}$, is estimated through a multivariable variance analysis of the results. Regarding the effectiveness factor, $97 \%$ of the variance was attributed to the clearness index alone. Regarding the design parameter the variance was distributed among the clearness index (again the most significant variable), being followed by the seasonal variation and latitude to a smaller extent. These results are shown in Figures $3 \mathrm{a}$ and $3 \mathrm{~b}$ below.

Figure 4 displays how the effectiveness factor varies at different clearness index values. It is apparent that there is an approximately linear positive relation between effectiveness factor and clearness index. The predicted mean effectiveness factor of 0.82 for a clearness index of 0.7 agrees with the results of Applebaum [2], which were obtained taking only into account an average daily variation of solar radiation in a clear sky day.

Figure 5 shows the dependence of the design parameter on the clearness index and latitude for different seasons of the year as well as for the entire year. The orientation of the contour lines (roughly vertical) for the higher clearness index values demonstrate that in such cases the effect of latitude is very small with respect to the design parameter. This is more or less so for all seasons of the year.

The values of $s$ and $p$ for the optimum arrangement of the PV system is estimated based on the values of a single PV unit according to the following relations:

$$
\begin{aligned}
s \cdot U_{\mathrm{mp}, u} & =U_{\mathrm{th}}+R_{\mathrm{eq}, \mathrm{PV}} \cdot p \cdot I_{\mathrm{mp}, u} \\
s \cdot p & =c t=\text { No of units. }
\end{aligned}
$$




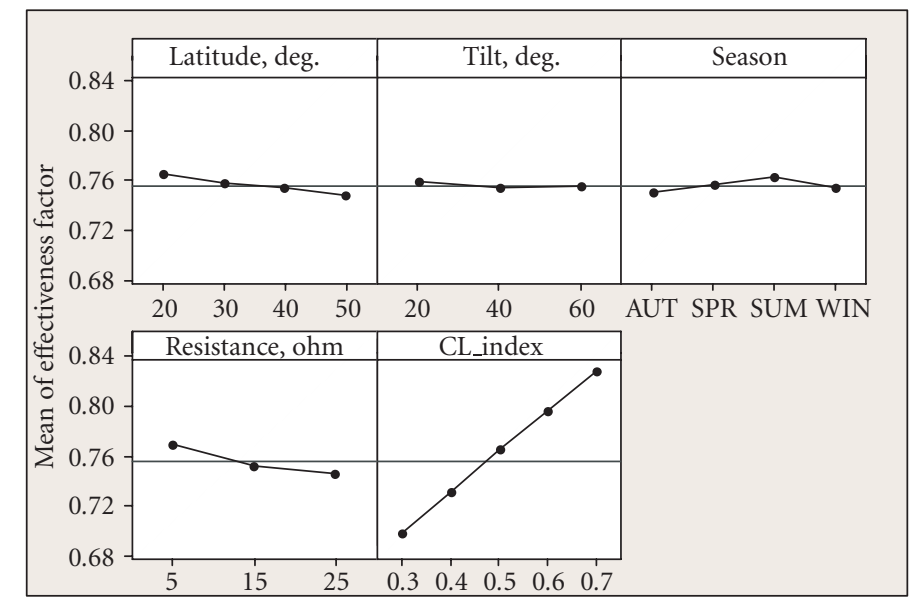

(a)

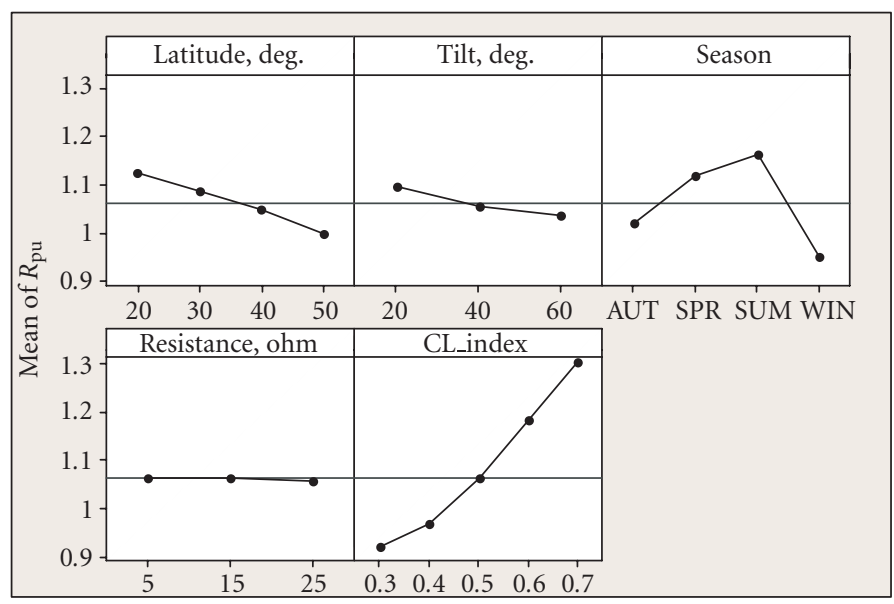

(b)

Figure 3: Main effects plots for (a) effectiveness factor and (b) design parameter.

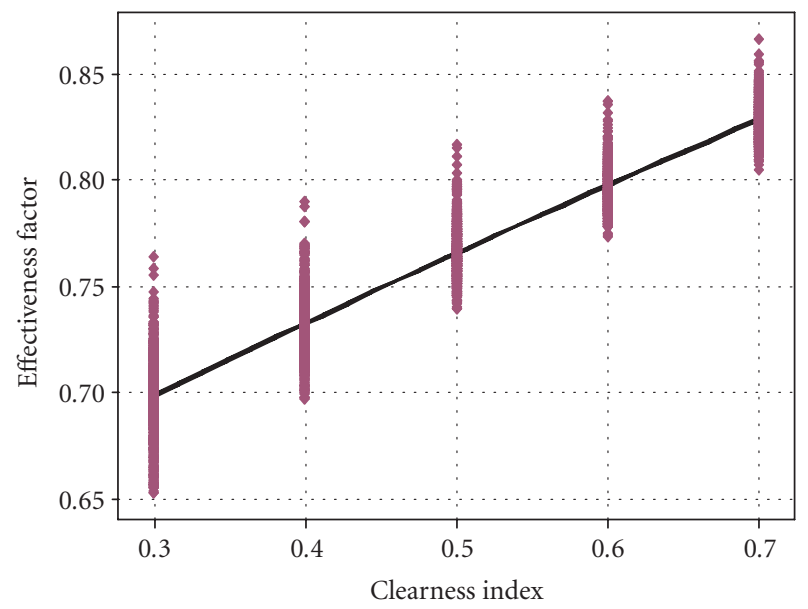

FIGURE 4: Effectiveness factor variability at various clearness indexes.
The general procedure for determining the optimum arrangement of a PV system is shown schematically in Figure 6.

\section{CONCLUSIONS}

A novel method has been developed for the investigation of the effectiveness factor and optimum arrangement of a PV system directly coupled to a load. The main advantage of the method is that it accounts for the variance of solar radiation not from just a single day but from a longer period of time as it should be in a real application. The method has been applied to Thevenin's equivalent loads utilizing per unit reduced parameters which lead to a generalized designing procedure. It is found that the mean effectiveness factor varies approximately linearly with the clearness index. Moreover, the simulation results showed that for a high clearness in$\operatorname{dex}(\sim 0.7)$, the mean effectiveness factor can take values as 


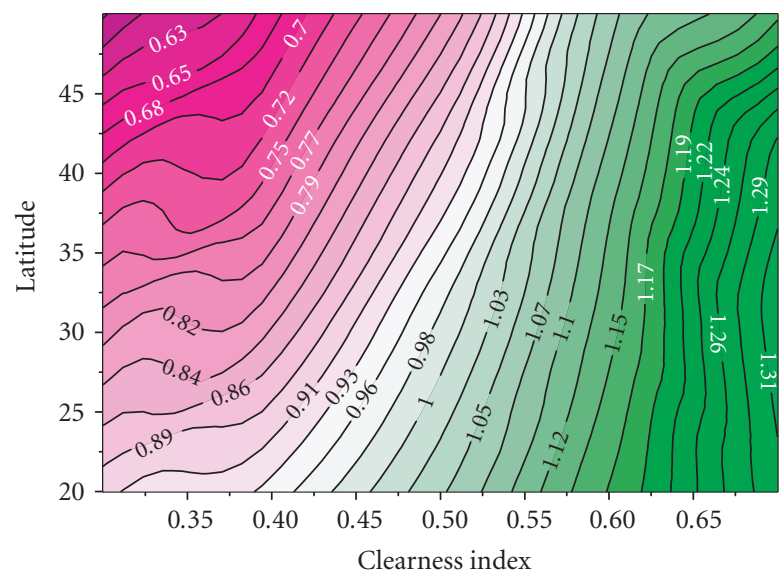

(a) Winter

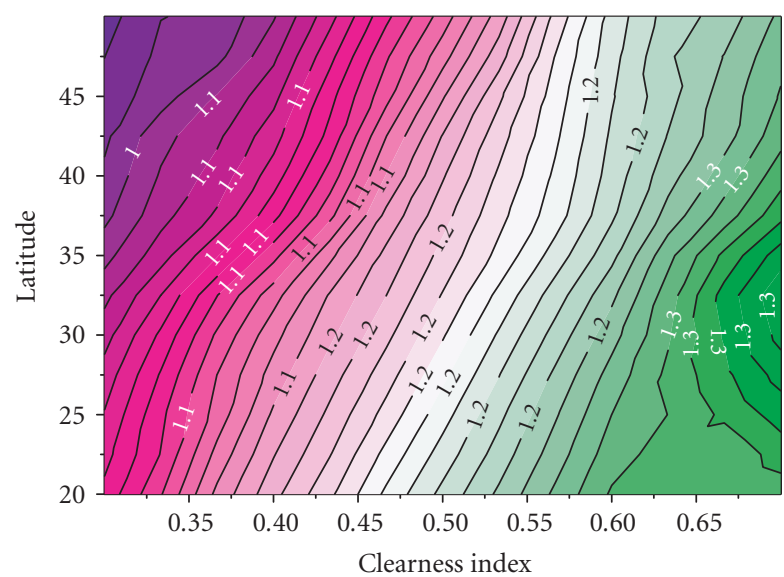

(c) Summer

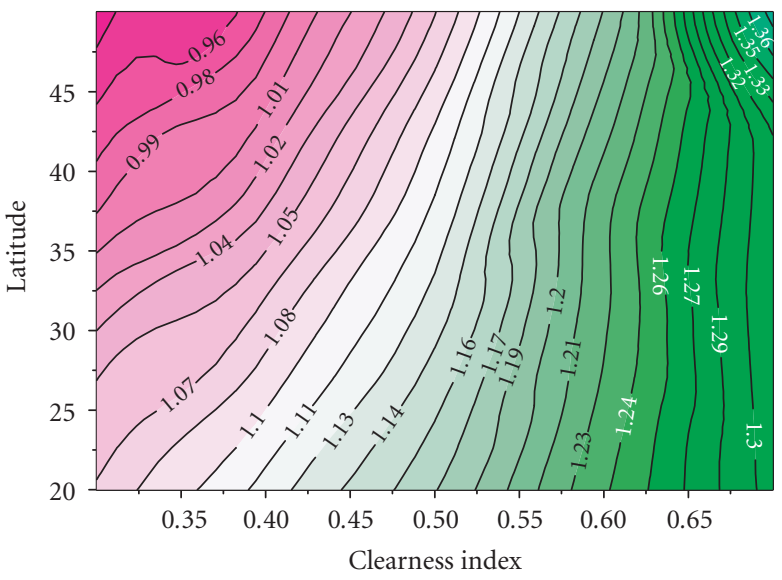

(b) Spring

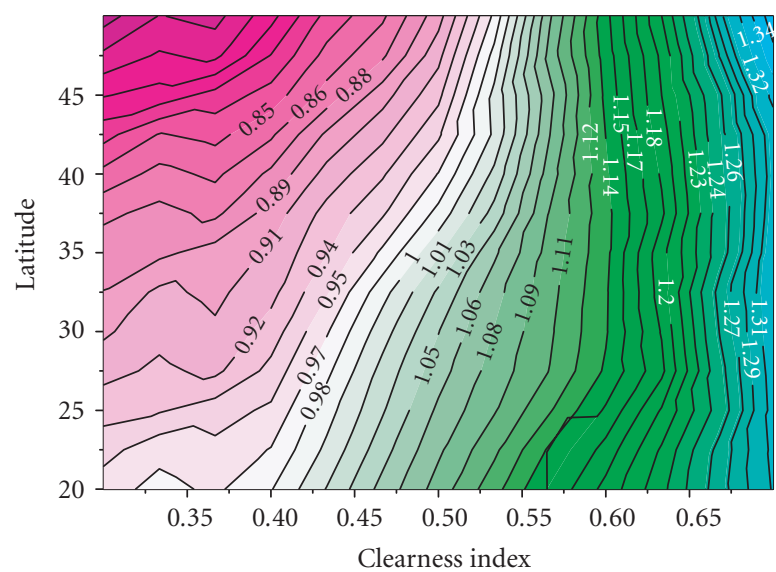

(d) Autumn

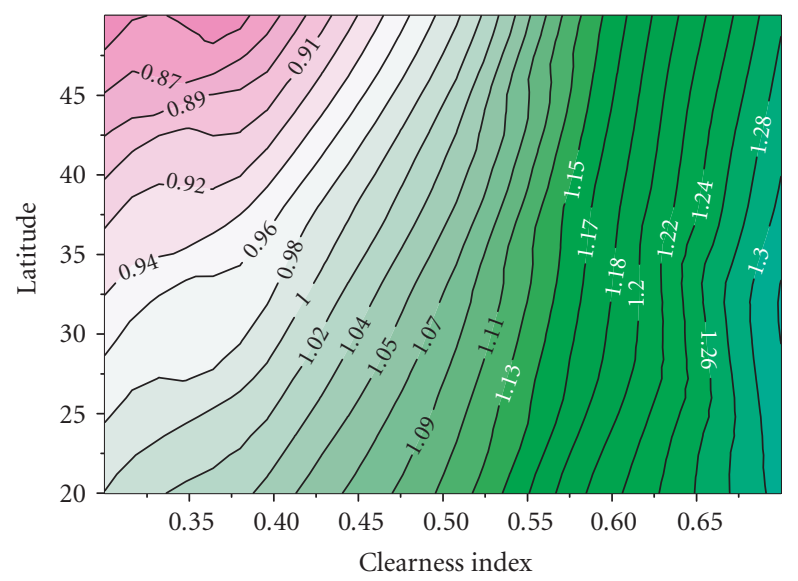

(e) Year

FIGURE 5: Contour plots of the design parameter, $R_{p u}$, versus latitude and clearness index for different seasons and for the entire year.

high as $\sim 82 \%$ if only a proper PV arrangement is employed. The comprehensive plots produced by the present simulations allow the reduced design parameter, $R_{p u}$, (dictating the optimum PV system arrangement) to be easily deduced. Therefore, the present work represents a short-cut method for field engineers and PV experts. 


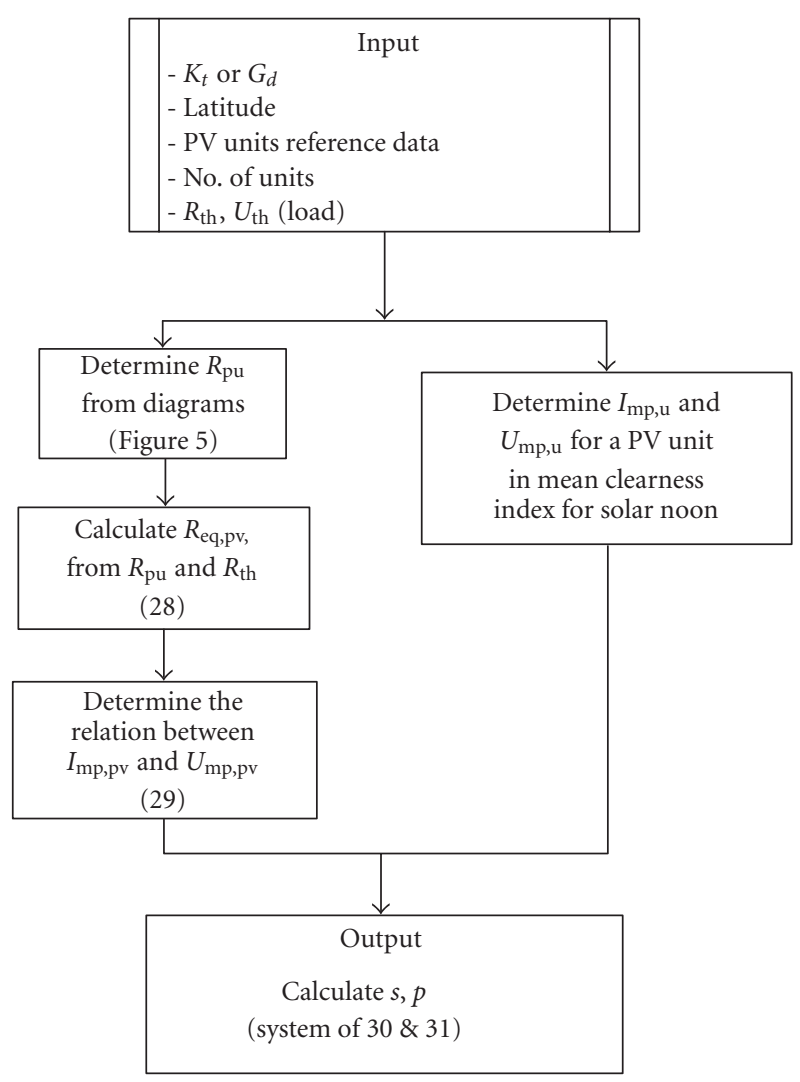

FIgURE 6: Block diagram of design procedure.

\section{ACKNOWLEDGMENT}

This work has been funded by the Greek Ministry of Education (program ARCHIMIDES I).

\section{REFERENCES}

[1] Energy Efficiency and Renewable Energy Network (EREN), http://www.eren.doe.gov/.

[2] J. Appelbaum, "The quality of load matching in a directcoupling photovoltaic system," IEEE Transactions on Energy Conversion, vol. 2, no. 4, pp. 534-541, 1987.

[3] M. M. Saied and M. G. Jaboori, "Optimal solar array configuration and DC motor field parameters for maximum annual output mechanical energy," IEEE Transactions on Energy Conversion, vol. 4, no. 3, pp. 459-465, 1989.

[4] K. Y. Khouzam, L. Khouzam, and P. Groumpos, "Optimum matching of ohmic loads to the photovoltaic array," Solar Energy, vol. 46, no. 2, pp. 101-108, 1991.

[5] Q. Kou, S. A. Klein, and W. A. Beckman, "A method for estimating the long-term performance of direct-coupled PV pumping systems," Solar Energy, vol. 64, no. 1, pp. 33-40, 1998.

[6] K. Y. Khouzam, "Optimum load matching in direct-coupled photovoltaic power systems-application to resistive loads," IEEE Transactions on Energy Conversion, vol. 5, no. 2, pp. 265-271, 1990.

[7] J. A. Duffie and W. A. Beckman, Solar Engineering of Thermal Processes, John Wiley \& Sons, New York, NY, USA, 1991.

[8] P. Bendt, M. Collares-Pereira, and A. Rabl, "The frequency distribution of daily insolation values," Solar Energy, vol. 27, no. 1, pp. $1-5,1981$. 


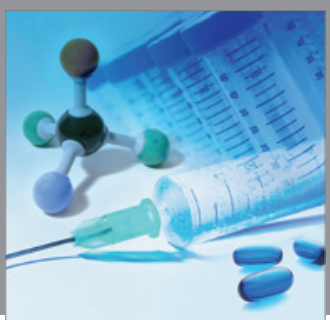

International Journal of

Medicinal Chemistry

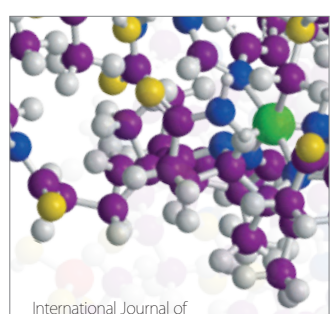

Carbohydrate Chemistry

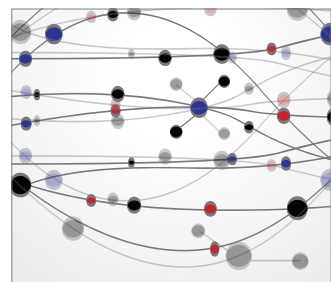

The Scientific World Journal
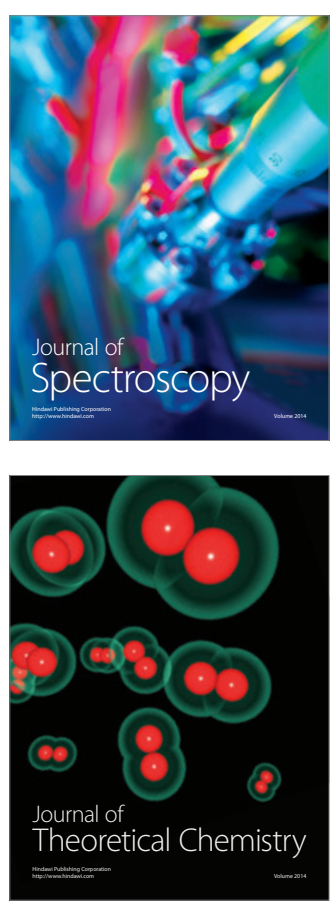
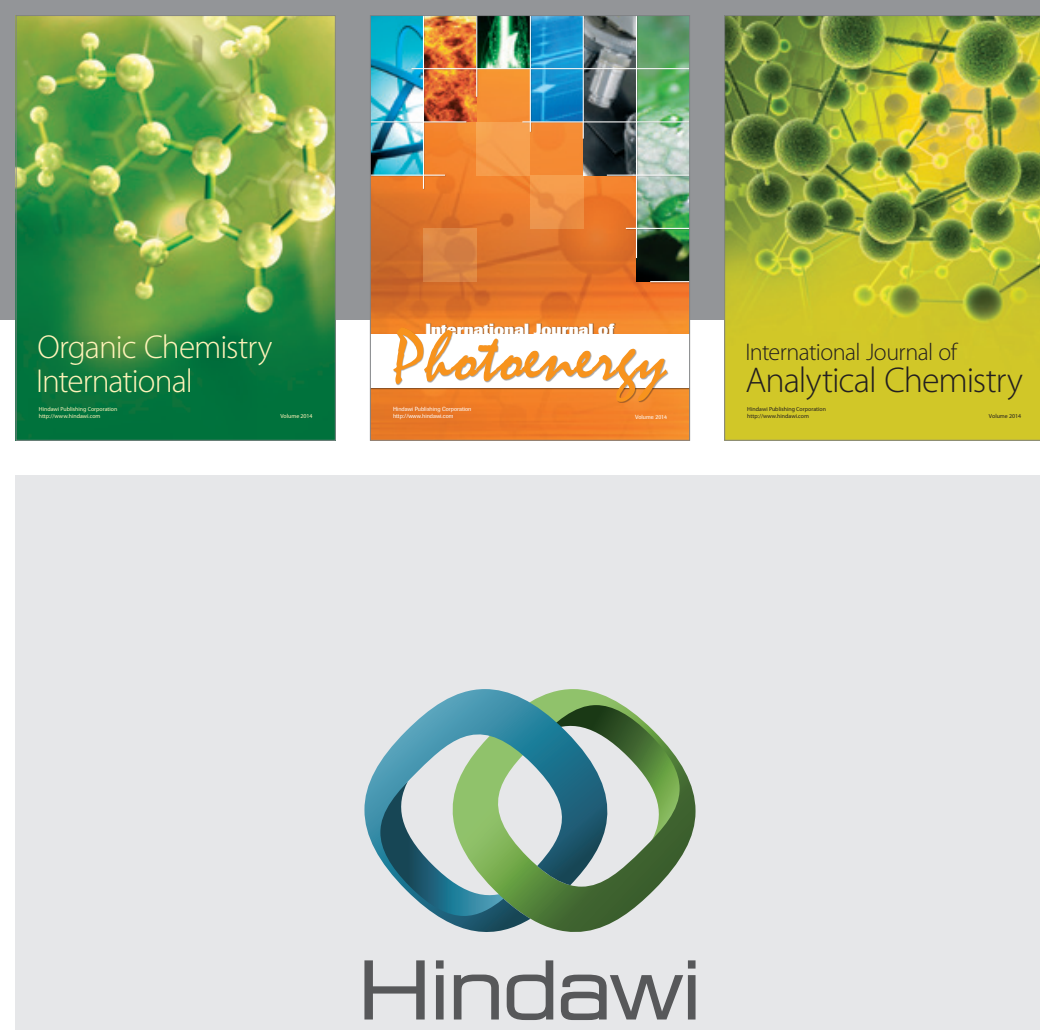

Submit your manuscripts at

http://www.hindawi.com
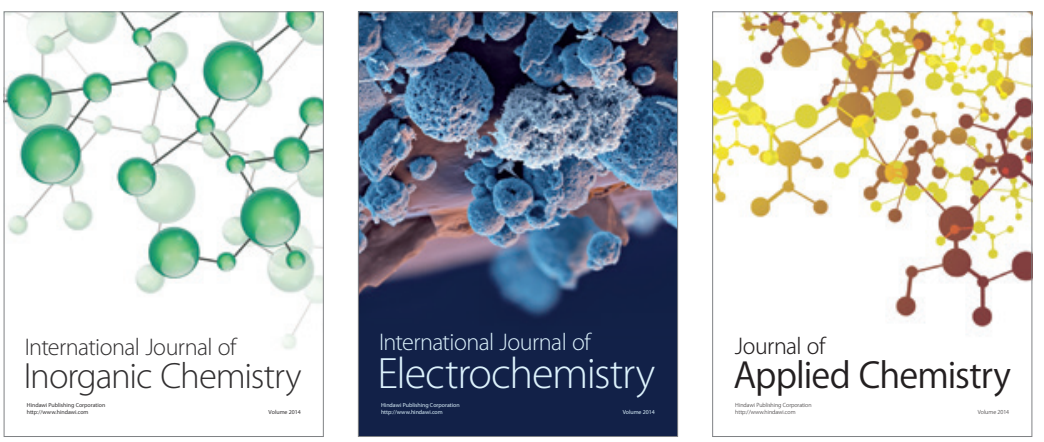

Journal of

Applied Chemistry
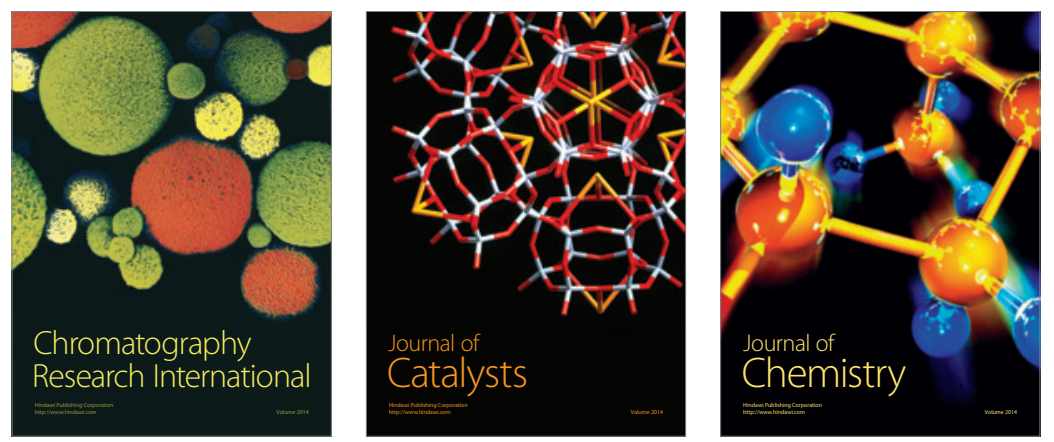
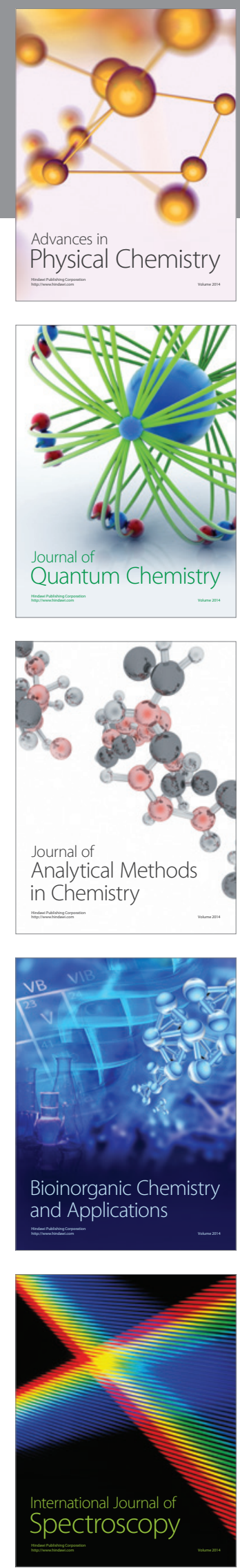